\title{
Relayed HOHAHA, a Useful Method for Extracting Subspectra of Individual Components of Sugar Chains
}

\author{
F. InAGaKI, ${ }^{*}$ I. ShImada, D. Kohda, A. SuZUKI, $\dagger$ ANd A. BaX $\ddagger$ \\ Department of Molecular Physiology and $\dagger$ Department of Membrane Biochemistry, The Tokyo \\ Metropolitan Institute of Medical Science, 18-22, Honkomagome 3-chome, Bunkyo-ku Tokyo 113, Japan. \\ and $\ddagger$ Laboratory of Chemical Physics, National Institute of Diabetes, Digestive and Kidney Diseases, \\ National Institutes of Health, Bethesda, Maryland 20892
}

Received March 8, 1988

The main difficulty encountered in the analysis of NMR spectra of sugar chains is the overlap of most sugar proton resonances except for reporter groups such as anomeric proton resonances ( 1 ). Therefore, NMR methods for extracting the proton resonances of each sugar component from an overlapping region are very useful. In previous studies, we applied multiple relayed COSY (2-5) and homonuclear Hartmann-Hahn spectroscopy (HOHAHA) $(6,7)$ to extract the subspectrum of each sugar component of glycolipids $(8,9)$, utilizing magnetization transfer from wellresolved anomeric proton resonances. In contrast to homonuclear multiple relay experiments, the HOHAHA experiment does not generate large amounts of multiplequantum coherence during the mixing period and it redistributes the entire integrated intensity of one proton among all $N$ protons in the same spin system. Hence, besides relaxation during the mixing time, the sensitivity of a 1D HOHAHA spectrum is reduced only by a factor $N$ relative to a conventional one-dimensional ' $\mathrm{H}$ spectrum. Magnetization transfer in the HOHAHA experiment is especially efficient when all couplings are of a similar order of magnitude. For example, for sugar residues such as Glc and GlcNAc which have couplings of $6-9 \mathrm{~Hz}$ all around the ring, complete subspectra can be obtained very efficiently.

If one of the couplings around the sugar ring is very small, it essentially blocks the Hartmann-Hahn flow of magnetization. For example, in Gal, GalNAc, and Fuc residues, magnetization is rapidly transferred among protons $\mathrm{H} 1$ through $\mathrm{H} 4$, but because of the typically very small coupling constant between $\mathrm{H} 4$ and $\mathrm{H} 5$ protons (1$1.5 \mathrm{~Hz}$ ), HOHAHA transfer to $\mathrm{H} 5$ is not very efficient. Moreover, any magnetization transferred to $\mathrm{H} 5$ is rapidly "diluted" because of further HOHAHA transfer to the usually fast relaxing $\mathrm{H} 6$ protons. Here we demonstrate that a combination of $\mathrm{HO}$ HAHA and the conventional ${ }^{1} \mathrm{H}-{ }^{1} \mathrm{H}$ relay mechanism can be used effectively to circumvent this problem.

The pulse sequence of $1 \mathrm{D}$-relayed HOHAHA is shown in Fig. 1, where magnetization is first transferred from $\mathrm{H} 1$ to $\mathrm{H} 4$ via $\mathrm{H} 2$ and $\mathrm{H} 3$ by HOHAHA using MLEV-

* To whom correspondence should be addressed. 


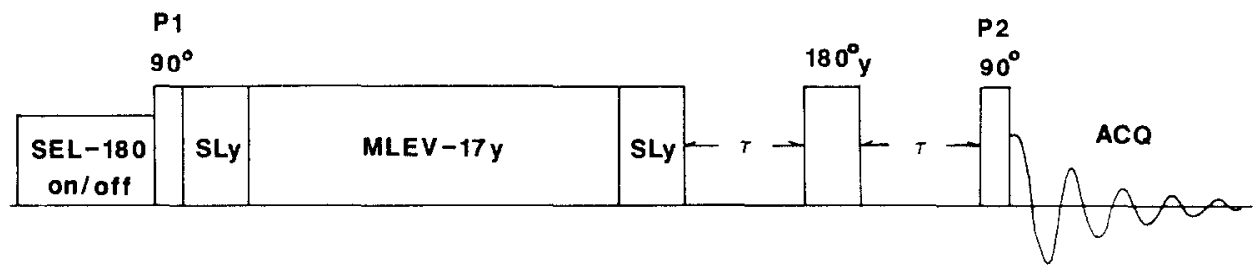

FIG. 1. Pulse sequence for the 1D-relayed HOHAHA experiment. P1, P2, and acquisition phases are cycled as follows; $\mathrm{P} 1\left(0^{\circ}, 180^{\circ}, 0^{\circ}, 180^{\circ}\right), \mathrm{P} 2\left(90^{\circ}, 90^{\circ}, 270^{\circ}, 270^{\circ}\right)$, and acquisition phase $\left(90^{\circ}, 270^{\circ}\right.$, $\left.270^{\circ}, 90^{\circ}\right)$.
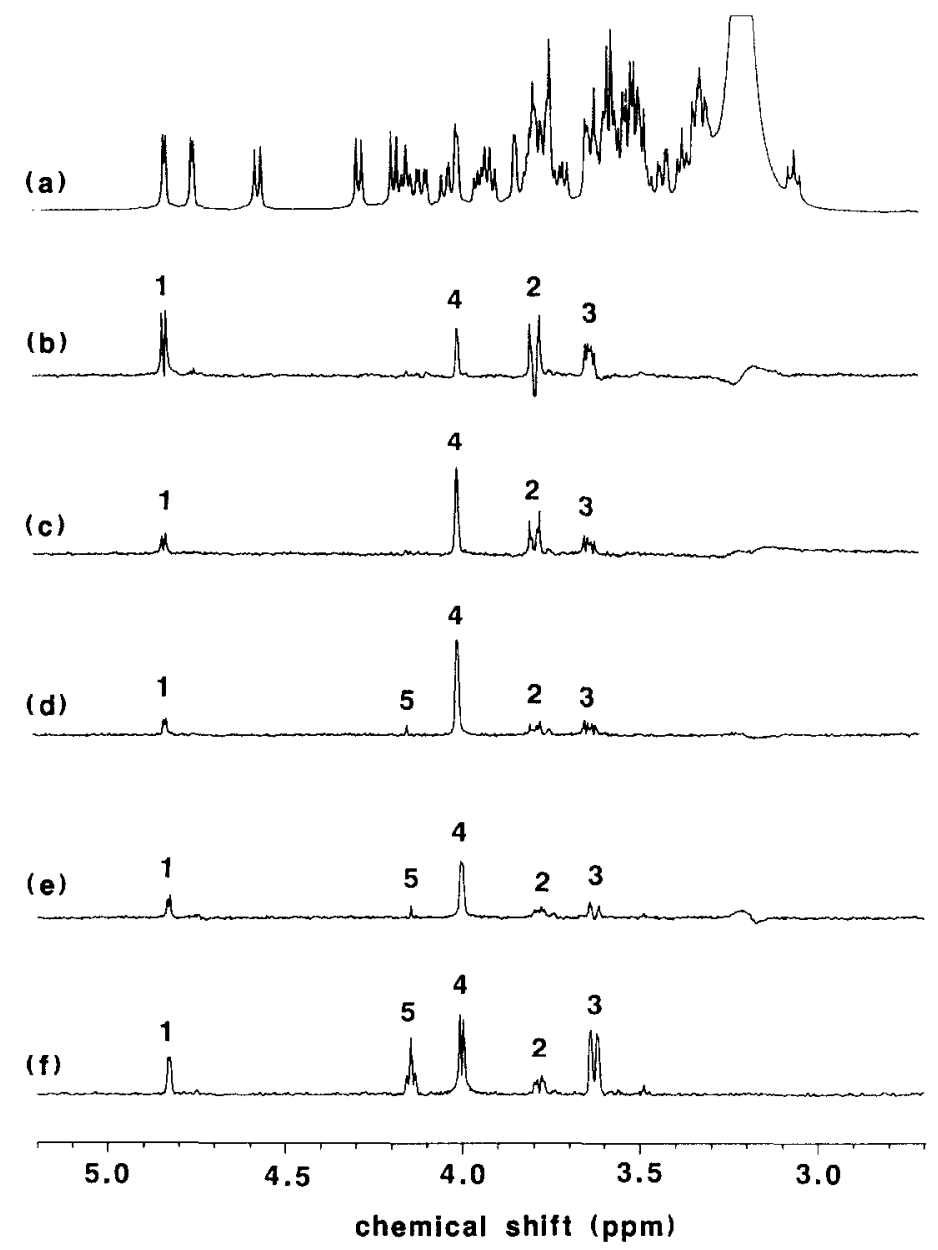

FIG. 2. Comparison of ID HOHAHA and ID-relayed HOHAHA spectra of Forssman antigen at 500 MHz. These spectra were obtained on a JEOL JNM-GX500 NMR spectrometer. The pulse sequence was generated using the PGX 200 pulse programmer. A $5 \mathrm{mg}$ sample of Forssman's antigen was dissolved in DMSO $/ \mathrm{D}_{2} \mathrm{O}(98 / 2)$ solution. The spectra were obtained at $60^{\circ} \mathrm{C}$. (a) Normal spectrum, 1D HOHAHA spectra with a mixing time of (b) $128 \mathrm{~ms}$, (c) $192 \mathrm{~ms}$, (d) $224 \mathrm{~ms}$, (e) $320 \mathrm{~ms}$, and (f) absolute-value mode 1D-relayed HOHAHA spectrum with a mixing time of $224 \mathrm{~ms}$ and a delay time of $100 \mathrm{~ms}(\tau=50 \mathrm{~ms})$. 
17 type mixing (6); magnetization of $\mathrm{H} 4$ is subsequently relayed to $\mathrm{H} 5$ by the conventional pulse-interrupted free-precession process. Similar to 1 D HOHAHA ( 7 , 10), the sequence starts with selective spin inversion of a preselected proton resonance in odd-numbered scans. The homonuclear decoupler is used for generating this $180^{\circ}$ pulse. In even-numbered scans, the decoupler is switched off. This ensures that in the difference spectrum only resonances from protons directly or indirectly coupled to the inverted proton will be present.

In the present study, we have applied relayed HOHAHA to extract the subspectra of the individual sugar components of Forssman antigen (GalNAc $\alpha 1-$ 3 GalNAc $\beta 1-3 \mathrm{Gal} \alpha 1-4 \mathrm{Gal} \beta 1-4 \mathrm{Glc} \beta 1-\mathrm{Cer})(11,12)$. Comparison of the efficiency
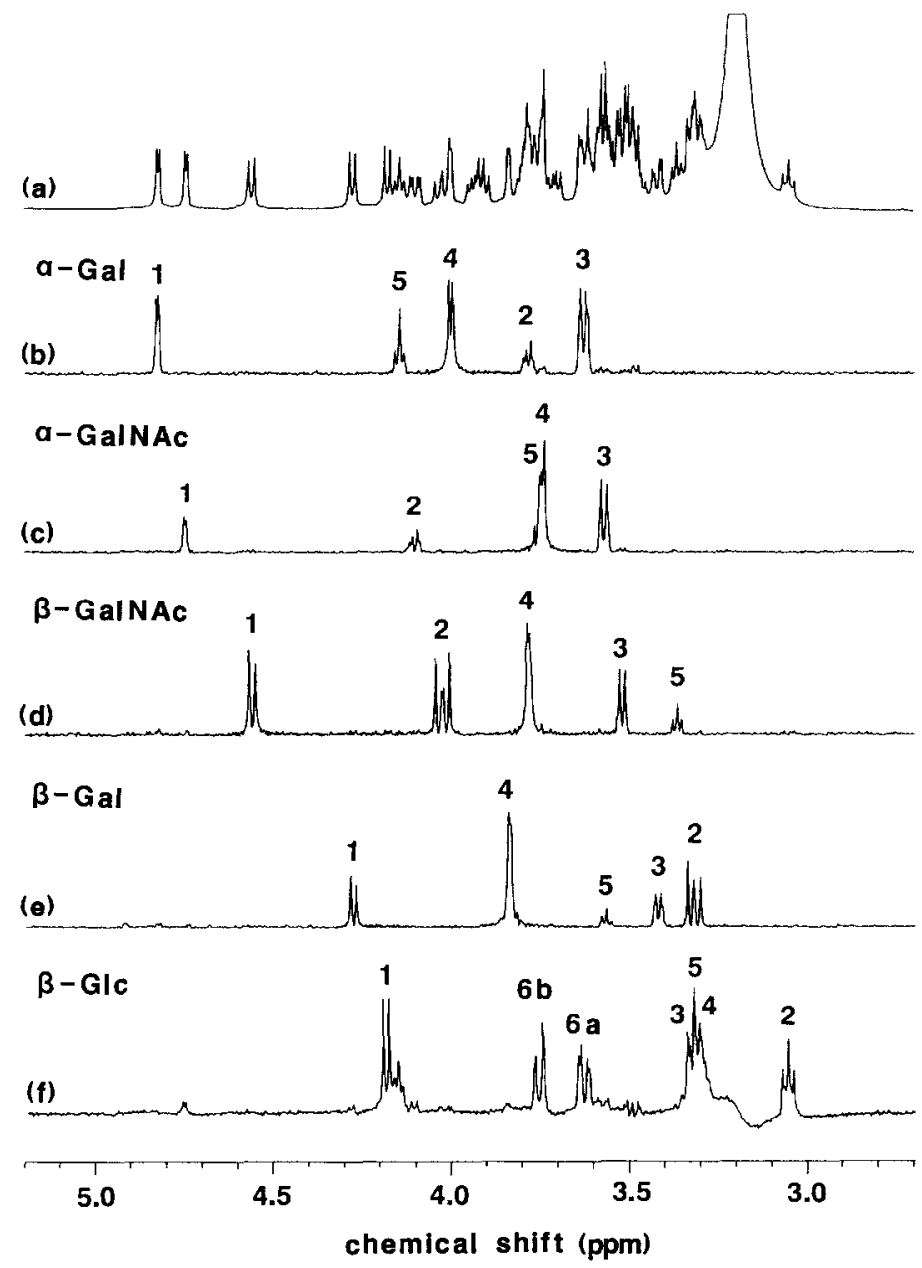

FIG. 3. Subspectra of individual sugar components of Forssman antigen. (a) Normal spectrum, 1Drelayed HOHAHA spectra of (b) $\alpha$-Gal, (c) $\alpha$-GalNAc, (d) $\beta$-GalNAc, (e) $\beta$-Gal, and (f) ID HOHAHA spectrum of $\beta$-Glc, where the anomeric proton of each sugar component was selectively inverted. The IDrelayed HOHAHA spectra are displayed in the absolute-value mode. 


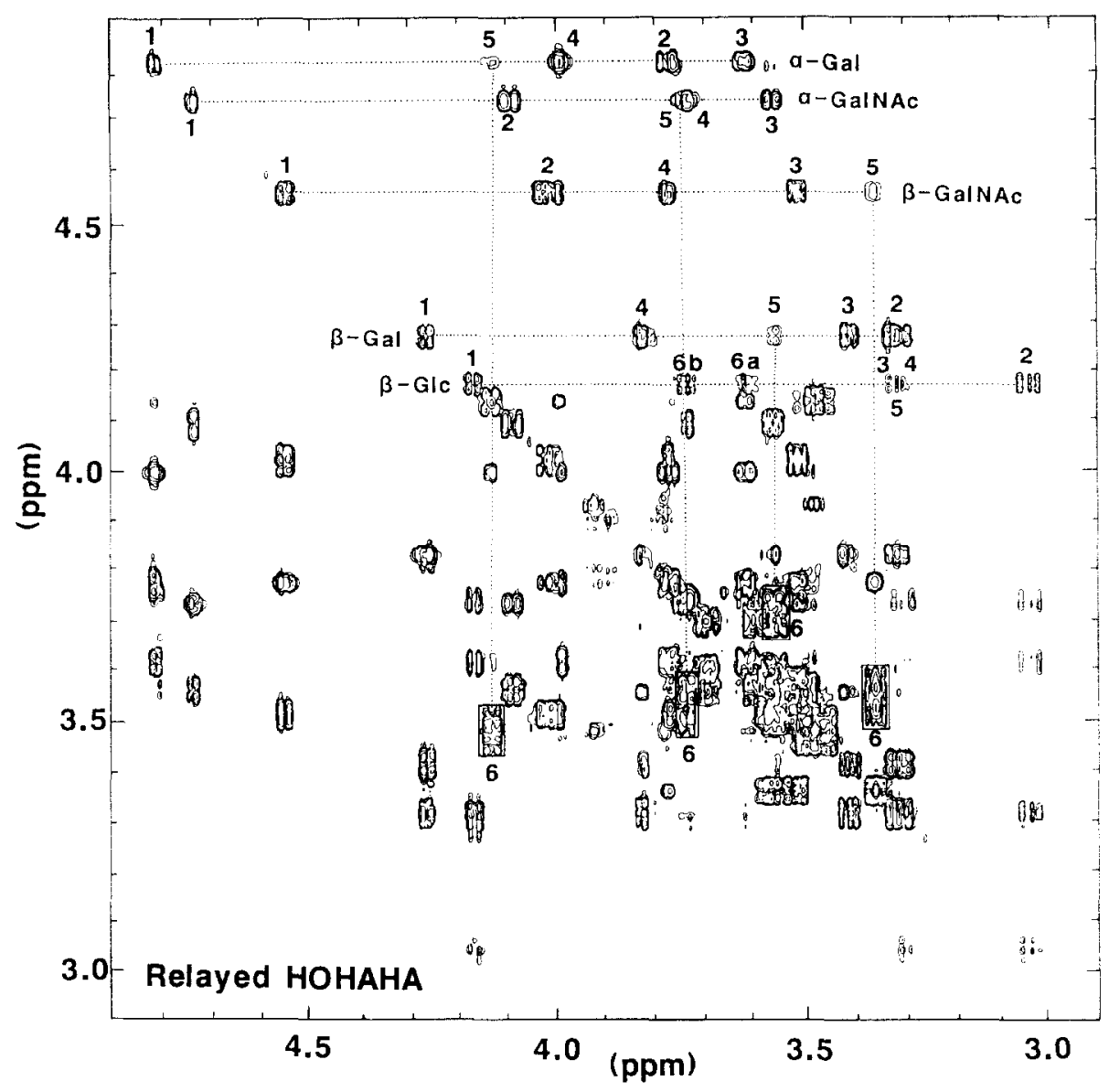

FiG. 4. Absolute value mode 2D-relayed HOHAHA spectrum of Forssman antigen.

of magnetization transfer by 1D HOHAHA and 1D-relayed HOHAHA is shown in Fig. 2, where the anomeric proton resonance of $\alpha$-Gal unit was selectively inverted. In 1D HOHAHA, the efficiency of magnetization transfer from $\mathrm{H} 1$ to $\mathrm{H} 2-\mathrm{II} 4$ was very good (Fig. 2b, 2c). The accumulated $\mathrm{H} 4$ magnetization transferred from $\mathrm{H} 1$ was maximal at a mixing time of $224 \mathrm{~ms}$ (Fig. 2d). However, with this mixing time, $\mathrm{H} 5$ proton resonance did not appear. Even with a longer mixing time of $320 \mathrm{~ms}$, only a very small signal of $\mathrm{H} 5$ appeared ( Fig. $2 \mathrm{e}$ ). Figure $2 \mathrm{f}$ shows a 1D-relayed HOHAHA spectrum with a mixing time of $224 \mathrm{~ms}$ for HOHAHA and a delay time of $100 \mathrm{~ms}$ for a relayed magnetization transfer step. In contrast to 1D HOHAHA (Fig. 2e), H5 shows up clearly in Fig. $2 \mathrm{f}$, showing that the efficiency of magnetization transfer from $\mathrm{H} 4$ to $\mathrm{H} 5$ is much better for 1D-relayed HOHAHA than that for 1D HOHAHA, although the same total mixing time was used for both experiments. A delay time longer than $100 \mathrm{~ms}$ did not improve the results. $S / N$ was worse due to magnetization decay during the long delay time. Therefore, in subsequent experiments, we set the delay time to $100 \mathrm{~ms}$. Figure 3 shows 1D-relayed HOHAHA spectra of Forssman 
antigen, where the anomeric proton resonance of each sugar component was selectively inverted. The mixing times were set to $224 \mathrm{~ms}$ for $\alpha$ anomers and $144 \mathrm{~ms}$ for $\beta$ anomers, respectively. In contrast to using the original ID HOHAHA experiment, all the proton resonances from $\mathrm{Hl}$ to $\mathrm{H} 5$ of $\mathrm{Gal}$ and GalNAc in Forssman antigen were extracted showing that relayed HOHAHA is a useful method for extracting the sugar proton resonances. Of course, the 1D-relayed HOHAHA can also be performed in a $2 \mathrm{D}$ version. Figure 4 shows a 2D-relayed HOHAHA spectrum of the sugar proton region of Forssman antigen. At the chemical shift of the anomeric proton resonance of each sugar component, cross peaks of $(\mathrm{H} 1, \mathrm{H} 2),(\mathrm{H} 1, \mathrm{H} 3),(\mathrm{H} 1, \mathrm{H} 4)$, and $(\mathrm{H} 1$, H5) were developed. Once the chemical shifts of $\mathrm{H} 5$ proton resonances of Gal and GalNAc were identified, $\mathrm{H} 6$ proton resonances were unambiguously assigned from the cross peaks of ( $\mathrm{H} 5, \mathrm{H} 6)$. Since spin couplings between those protons are usually large, we can observe relatively large cross peaks in the 2D-relayed HOHAHA spectrum as marked in Fig. 4. Thus, all the sugar proton resonances can be assigned to the individual sugar components. Once the sugar proton resonances are extracted, those protons can be used as structural probes to determine the connectivity between individual sugar residues.

\section{REFERENCES}

I. J. F. G. Vliegenthart, L. Dorland, AND H. van Halbeek, Adv. Carbohydr. Chem. Biochem. 41, 209 (1983).

2. G. W. Eich, G. Bodenhausen, ANd R. R. ERnst, J. Am. Chem. Soc. 104, 3731 (1982).

3. G. WAGNER, J. Magn. Reson. 55, 151 (1983).

4. A. BAX AND G. DROBNY, J. Magn. Reson. 61, 306 (1985).

5. M. IKURA AND K. HIKICHI, Carbohydr. Res. 163, 1 (1987).

6. A. BAX AND D. G. DAviS, J. Magn. Reson. 65, 355 (1985).

7. D. G. Davis and A. BAX, J. Am. Chem. Soc. 107, 7197 (1985).

8. F. INAGAKI, D. KOHDA, C. KODAMA, AND A. SUZUKI, FEBS Lett. 212, 91 (1987).

9. F. INAGakI, C. Kodama, M. SUZUKI, AND A. SUZUKI, FEBS Lett. 219, 45 (1987).

10. S. Subramanian and A. BaX, J. Magn. Reson. 71, 325 (1987).

11. S. ANDO AND T. Yamakawa, Chem. Phys. Lipids 5, 91 (1970).

12. B. SidDIQUI AND S. HAKOMORI, J. Biol. Chem. 246, 5766 (1971). 